SCHOLARS: Journal of Arts \& Humanities

[Peer-Reviewed, Open Access, Indexed in NepJOL]

Print ISSN: 2773-7829; e-ISSN: 2773-7837

Volume 1, August 2019, pp. 50-66

DOI: https://doi.org/10.3126/sjah.v1i0.34448

Central Department of English

Tribhuvan University

Kirtipur, Kathmandu, Nepal

www.cdetu.edu.np/ejournal/

\title{
Family Dynamics: An Intergenerational Study on Asian American Narratives
}

\author{
Nagendra Bahadur Bhandari \\ Department of English \\ Prithvi Narayan Campus, Pokhara, Nepal
}

\begin{abstract}
The relationship in Asian immigrant families ranges from intergenerational and intercultural conflict to mutual understanding over the period of the time. Shaped by different cultural contexts of native and host land, the first and second-generation immigrants have varying world views, perceptions and attitudes rendering conflicts of interests in their priorities. These differences are further widened by their generational differences. However, they negotiate their cultural differences and show mutual understanding, respect for differential priorities and flexibility for co-optation of diverse cultural practices. They involve in dynamic intergenerational relationship full of inconsistencies and contradictions, which keeps of changing in different contexts over the period of time. This article explores the dynamic relationship of the first and secondgeneration immigrants in Asian-American narratives: The Namesake by Jhumpa Lahiri, The Bonesetter's Daughter by Amy Tan, Native Speaker by Change rae Lee and Chorus of Mushrooms by Hiromi Goto. Both generation immigrant characters in these narratives constantly vacillate between the cultural spaces of their home and host countries in their negotiation of intergenerational relationship. This article analyzes the cultural vacillation of immigrants in the critical frame of Stuart Hall's cultural identity which he conceptualizes in his notion of being and becoming.
\end{abstract}

Keywords: Cultural identity, cultural root, diaspora, immigrant, Intergeneration

\section{Introduction}

The first and second-generation immigrants in Asian American narratives involve in ambivalent intergenerational and intercultural relationship in their cultural negotiation in the diaspora. The first-generation immigrants, who have migrated to the 
Family Dynamics: An Intergenerational Study 51

diaspora for their higher education and prospective careers, in their attempt of conserving native cultural identity, impose cultural practices of home land to their children who are born and brought up in the diaspora. The second-generation immigrants, the children of the first-generation, in their constant fascination to the Western lifestyle of their host country respond with reluctance and resistance to the cultural imposition of their parents. Such differential cultural priorities which are further widened by cultural differences between the Eastern Asian and the Western American cultures render conflicts in Asian immigrant families. However, the cultural priorities of the both generation immigrants involve in a dynamic process negotiation vacillating between the cultural practices of the home and host countries. In such cultural negotiation the immigrant parents and children foster harmonious relationship by showing mutual understanding, respecting for differential priorities and co-opting diverse cultural practices flexibly.

Both generation immigrants, without totally forsaking one culture while following the other, tend to live with the shared cultures, partly Western and partly Eastern involving in the complex intergenerational relationship. The Asian American narratives The Namesake by American Indian writer Jhumpa Lahiri, The Bonesetter's Daughter by Chinese American writer Amy Tan, Chorus of Mushrooms by Japanese American writer Hiromi Goto and Native Speaker by Korean American writer Change rae Lee explore intergenerational and cultural negotiation in Asian immigrant families. Such cultural vacillations substantiates Stuart Hall's notion of cultural identity which he conceptualizes in his concept of 'being' and 'becoming' that substantiates cultural vacillations of immigrants.

\section{Cultural Identity}

Broadly, there are three different conceptualizations of cultural identity. The first conceptualization, which is known as essentialism, emphasizes on the essential characters of a cultural community which an individual inherits as a member of the community. Conversely, the second conceptualization asserts that cultural identity of an individual evolves out of social interaction in course of living. This social constructivist approach denies possessing any essential characters which are immutable. The third approach which is postulated by Stuart Hall merges both the essentialist and social constructivism approaches in his proposition of cultural identity. He equally emphasizes the role of cultural genealogy and social interaction in the formation of an individual's cultural identity.

The essentialist approach of cultural identity argues that every community possesses certain essential and core values "that determine its uniqueness and specificity" (Petkova 17). The essential values which they terms as "a social or cultural spirit of community" function as a "higher existential essence" of the community (17). 
Family Dynamics: An Intergenerational Study 52

They are considered as eternal aspects of reality and they are independent of human beings beyond time and place. Living in the community, an individual internalizes these essential values. Apparently, the identification with the community is "considered to be a natural psychological phenomenon inherent in every individuals” (17). In this sense, inheriting essential communal values and norms, an individual acquires a cultural identity that transcendent time and space. This approach, however, undermines the role of personal experience and social interaction in forming cultural identity of an individual.

Critiquing the essentialist's emphasis on essential values, social constructivism underlines on social interaction of an individual for the formation of cultural identity. This approach rejects "the existence of essential or innate features" (17) of a cultural community that transcendent time and space. Rather, it claims that cultural identity of an individual is a social construct. This approach claims that cultural communities and cultural identities are "continuously constructed, shaped and reshaped by individuals" (19). Moreover, nations and sometimes even ethnicities are presented as the result of conscious and deliberate social engineering (Kedourie 1). So, theorists like Benedict Anderson and Erik Hobsbawn coin terminologies like "imagined communities" (Anderson 6) and "Invented Tradition" (Hobsbawn 1) to refer to national and cultural communities. In such social interactions, an individual may take up different cultural identities in different social and cultural context and their cultural identity undergoes in a constant process of formation and reformation.

There is nothing essential and permanent in social constructivism's approach of cultural identity. In contrast, an individual involves in a constant process of negotiation with multiple social and cultural allegiances. Floya Anthias succinctly elaborates that an individual's cultural identity comprises a number of aspects, for instances ethnicity, religion, language, nationality, gender, sexuality and social class. These aspects intersect, that is, the different aspects interrelate and crisscross within an individual's life and in social interactions. As a result, cultural identity is considered as unstable and plural in this perspective. However, this approach ignores the shared cultural values and common historical experience of a community which provide a constant reference for defining cultural identity of an individual.

Incorporating both approaches, essentialism and social constructivism, Hall postulates a third approach of cultural identity. He succinctly conceptualizes the cultural identity of immigrants in his postulation of being and becoming. The concept of being aligns similarities among a community of people, a sense of oneness in the underlying structure. People with a shared history and ancestry consciously maintain stable references of cultural identity beneath fleeting distinctions in the manifest: "our cultural identities reflect the common historical experiences and shared cultural codes which provide us, as 'one people', with stable, unchanging and continuous frames of reference 
Family Dynamics: An Intergenerational Study 53

and meaning, beneath the shifting divisions and vicissitudes of our actual history" (Hall 223). The oneness is understood as fixed reference and meaning which reflects the general shared cultural codes and common historical experiences. However, this definition overlooks the dynamic process only emphasizing the authentic stable reference of cultural identity.

Hall's second definition of "cultural identity" emphasizes both similarities and the differences amongst an imagined cultural group.

Cultural identity, ... is a matter of 'becoming' as well as of 'being'. It belongs to the future as much as to the past. It is not something which already exists, transcending place, time, history and culture. Cultural identities come from somewhere, have histories. But, like everything which is historical, they undergo constant transformation. Far from being eternally fixed in some essentialised past, they are subject to the continuous 'play' of history, culture and power. (225)

Hall's contingent and historical identity enters an ongoing process of 'becoming' as well as of 'being'. It equally belongs to both the future and the past. Depending on the pregiven and pre-determined aspects only partially define identity. Although historical, it changes in and through power relations that are spatial and cultural. Both being and becoming conjointly create cultural identity of immigrants in the diaspora. Apparently, both generation immigrants consistently vacillate between their being; cultural practices of their land of origin and becoming process; adoption of the cultural practices of the host land involving in the complex intergenerational relationship in matter of their preferred cultural practices which often remain fluid and unstable.

\section{Intergenerational Dynamics: Parents-Children Conflict}

The strain parents-children relationship in immigrants' family is the result of “cultural differences between parents' home-country values, norms and behavioral patterns and the mainstream... culture" (Foner and Dreby 547). For instances, the firstgeneration immigrants who are from the Eastern countries differ sharply from their children, who are brought up in the West, in a matter of parental authority in children's lives. Such conflict is quite evident in Chinese-American mother LuLing and her daughter Ruth's relation in Tan's The Bonesetter's Daughter. As a typical Chinese mother, LuLing is strict, strong and authoritative. In fact, "in a traditional Chinese mother-daughter relationship, the mother has the total control of her daughter and a good daughter is supposed to be unconditionally obedient to the will of her mother" (Pu 12). Shaped by her Chinese being, LuLing wants a submissive daughter with total loyalty. Conversely, Ruth is grown up embracing the Western cultural practices of her host country which emphasizes on individuality and freedom. So, she rebels against her 
Family Dynamics: An Intergenerational Study 54

mother's authoritative behavior. These differing cultural values often render clash in the mother-daughter relation.

The Chinese American mother LuLing, who is shaped by Chinese upbringing, feels that: "a daughter should have no secret from a mother" (Tan 157) and secretly looks into the diary of her daughter. Knowing mother's peeping in her personal diary, she makes an assault in her diary: "STOP!!! PRIVATE!!! IF YOU ARE READING THIS YOU ARE GUILTY OF TRESPASSING!!! Yes! I DO MEAN YOU!” (123). The mother- daughter dispute culminates when LuLing finds Ruth smoking in her bedroom. Ruth is so upset by such surveillance of her mother that she even wishes her mother would be dead. She writes in her diary that "you talk about killing yourself, so why don't you ever do it? I wish you would. Just do it, do it, do it! Go ahead, kill yourself!” (124). She believes that LuLing would read it. Obviously, the differential cultural values render conflict in parent-children relationship in immigrant families. The daughter Ruth, who adopts the Western cultural values which "typically encourage autonomy and independence" in her becoming process whereas her mother LuLing remains preoccupied with her being; Eastern cultures that "tend to value family connectedness and interdependence” (Giguere 24). These cultural differences of the home and host country are largely responsible for the clashes in the parents-children relation in the Asian immigrant families.

The growing sense of individualism and independence of the children like their Western peers lead them to confront their parents' preoccupation with the Eastern notion of family interdependence. They expect their parents to manage their personal matters themselves. However, Ruth's mother expects her daughter to be faithful and assist in her problems. Once Ruth confronts her mother: "If it bothers you so much, you take care of it" (Tan 46) on her mother's doubt about her help. Hearing this, her mother reacts: "You wish I dead? You wish no mother tell you what to do? Okay, maybe I die soon!” (46). Ruth feels that "she seems to do things only to annoy or embarrass her daughter" (Vizan 219). Obviously, the expectation of mother and the reaction of daughter are the result of two different cultural values. Brought up in Chinese culture, LuLing expects unconditional submission from her daughter and total control over the daughter's life which clashes with the sense of individualism of her daughter. Consequently, the secondgeneration immigrants expect their parents would get changed adopting cultural practices and values of their host land.

Some of the second-generation immigrants want to enjoy open and friendly relation with their parents in their home in the diaspora like their White schoolmates. For instance, Henry in Lee's Native Speaker, once recalls, "I so wanted to be familiar and friendly with my parents like my white friends were with theirs” (Lee 221). He does not like his childhood upbringing under his Korean American parents whose parenting is 
Family Dynamics: An Intergenerational Study 55

more influenced by their being; Korean cultural upbringing. Unlike the free and open Western manner, Henry's parents want their child to "speak quietly and little" (Lee 182) and emphasizes on emotional restraint, tolerance and patience. As a result, Henry envies other children who are grown up in a liberal environment. He remembers that he:

used to wish that [he] were more like [his] Jewish and Italian friends, or even the black kids who hung out in front of [his] father's stores; [he] was envious of how they'd speak so confidently, so jubilantly celebrate the fact with their hands and lips and tongues, letting it all hang out...for anybody who'd look and listen. (182)

As a child, Henry expresses his jealousy on the other children who enjoy their freedom. He harbors a keen passion for a free and liberal domestic environment where he can enjoy his freedom without restriction and fear of the elders in his childhood. Growing up in the Western cultural milieu, the children want to enjoy their lives without parental interference in their personal matters.

Unlike her daughter's expectation, LuLing, in The Bonesetter Daughter, wants to play a decisive role in the life of her daughter Ruth as a typical Chinese mother. When Ruth grows up, she begins to take her decision of her own which upsets her Chinese American mother. For instances, her decision of living with her boyfriend Art saddens her mother because it violates Chinese customs of marriage and diminishes the role of mother. Similarly, LuLing's dissatisfaction surfaces when Ruth cannot manage much time to visit her because of her busy schedule. LuLing sarcastically remarks that: "So busy, so success" (Tan 44). She further says: "Not free ... because every minute must charge money. What I should pay you, five dollar, ten dollar, then you come see me” (44). Her sarcasm reveals Chinese American mother's dissatisfaction on diminishing role in the life her daughter. She wants: "to be essential, as a mother should be" (344). Her concern for the Eastern cultural values of "family connectedness and interdependence" contradicts with her daughter who is influenced by the Western culture which encourages "autonomy and independence" (Giguere 24). Moreover, the children show reluctance and sometimes even resistance to comply with their parents' imposition of the cultural values of their ancestral land.

Most of the first-generation immigrants parents tend to act as a cultural transmitter of their homeland to their children who are brought up imbibing the Western cultural values. In their attempt of familiarizing their children with their being, the immigrant parents expose their children with native rituals and cultural heritage. In The Namesake, parents Ashima and Ashoke take their children to Indian cultural shows like Kathakali; a form of Indian classical dance performance or recital of Sitar; a classical Indian musical instrument at the memorial hall. In the same way, Ashima takes her children to the worship of Durga; the goddess of power and Saraswati; the goddess of 
Family Dynamics: An Intergenerational Study 56

education. Lahiri observes: “during pujos, scheduled for convenience on two Saturdays a year, Gogol and Sonia are dragged off to a high school or a Knights of Columbus hall overtaken by Bengalis, where they are required to throw marigold petals at a cardboard effigy of a goddess and eat bland vegetarian food" (64). Similarly, when Gogol is in the third grade, his parents send him to Bengali language and culture lessons twice a month in which he reads "handouts written in English about the Bengali Renaissance and the revolutionary exploits of Subhas Chandra Bose” (66). Exposing with such cultural heritage of their origin, parents want their children would imbibe some essence of their being. However, the children gradually resist such imposition of their parents when they grow old and begin to adopt the Western cultural values of their host country.

The parents are anxious about their children adoption of Western values and lifestyle of their host country. They "are worried that their children have too much freedom, too little respect for authority and too many unfavorable stimuli in school, on the street and on the television screen at home" (Zhou 28). In their anxiety of their children's Westernization, they also oppose their children's interracial relationship and marriage. In The Namesake, Ashima's reaction to her son Gogol's white girlfriend Maxine reveals parents' negative attitude to the white partner of their children. When Gogol brings her in his house:

Ashima doesn't want her for a daughter-in-law. She'd been startled that Maxine had addressed her as Ashima and her husband as Ashoke. And yet Gogol has been dating her for over a year now. By now Ashima knows that Gogol spends his nights with Maxine, sleeping under the same roof of her parents, a thing Ashima refuses to admit to her Bengali friends. (Lahiri 93)

Ashima is shocked when her son's American girlfriend calls her with the first name. A younger member calling the elder with the first name contradicts her Indian cultural upbringing. In addition, the first-generation immigrant parents expect their children "to marry within the ethnic group" (Foner 6). However, the Asian American parents vary in their attitudes in their children's adoption of the Western cultural values. Some of them even facilitate their children's assimilation into the mainstream culture of the host society.

Unlike many of the first-generation immigrant parents, Keiko, in Chorus of Mushrooms facilitates her daughter Murasaki to get into cultural space of their host country Canada. She attempts to raise her daughter according to the Canadian way of life so that she can be part of the mainstream society. Keiko thinks:

It is too confusing for a child to juggle two cultures. Two sets of ideals. If you want a child to have a normal and accepted lifestyle, you have to live like everyone else. This is nothing to do with shame of one's own 
Family Dynamics: An Intergenerational Study 57

culture, but about being sensible and realistic. If you live in Canada, you should live like a Canadian and that's how I raised my own daughter.

It's very simple, really. (Goto 189)

Keiko insists on the Canadian culture as she aspires in "forgetting her Japanese identity in order to feel at home in her new country" (Ponce 74). Consequently, Kekio assists her daughter Murasaki in adopting the Western cultural values by exposing with the mainstream culture since her childhood.

Keiko's attempt of westernizing her daughter goes beyond domestic realms. In public, Keiko even forces her daughter to regulate her biological traits as per the demand of the mainstream Canadian society. When Murasaki is selected for the performance of Alice in Wonderland, her teacher explains Keiko, "Well, Alice is a story about an English girl, you know. An English girl with lovely blonde hair. And strictly for the play, you understand, Muriel will have to have blonde hair or no one will know what part she is playing. You simply cannot have an Alice with black hair” (Goto 177). Keiko enthusiastically agrees to the teacher's request, even suggesting that Murasaki would dye her hair instead of simply wearing a wig. The teacher's request is the working strategies of homogenization of others within the White dominant society so that difference is categorized and controlled from within (Beautell 11). Apparently, Keiko willingly complies in the process of homogenization of the mainstream society of her host country. However, her daughter Murasaki; the second-generation immigrant opposes her parent's assimilationist attitude and want to explore her being, that is, her cultural origin.

Murasaki counters her mother's attempt of assimilating her daughter into their host culture to avoid bicultural confusion of living as an immigrant in the diaspora. In fact, her mother thinks that "it is too confusing for a child to juggle two cultures" (Goto 189). However, Murasaki has different experience than her mother's perspective:

I wasn't given the chance to choose. I feel a lot of bitterness about how I was raised, how I was taught to behave. I had a lot of questions about my heritage, but they were never answered. The place where we lived didn't foster cultural difference. It only had room for cultural integration. If you didn't abide by the unwritten rules of conduct, you were alienated as an other, subject to suspicion and mistrust. (189)

Following the Canadian lifestyle does not qualify her to be a genuine Canadian. Murasaki feels that "people think certain things of you just because your hair is black" (189). Apparently, the second-generation's quest of belonging into host society is interrogated due to the biological and cultural inheritances. Unlike in other immigrant families, this conflict in the Japanese immigrant family manifests the second-generation immigrant's fascination to her cultural root while her mother shows an obsession to the lifestyle of the host country. 
Family Dynamics: An Intergenerational Study 58

Unlike Murasaki, Ruth gets offended with her mother LuLing's reluctance in acculturation in their host country in The Bonesetter's Daughter. She feels ashamed of her mother's constant preoccupation with her Chinese origin and denies her recognizing her publicly once in her school among her friends. In her break time, when Ruth tries to slide down in an unusual manner LuLing shouts in English with Chinese accent "No! Luyi, stop! What are you doing? You want to break your body in half?” (Tan 63). Then, one of Ruth's friends asks: "Is that your mother?” (63). Her friend is surprised by her Chinese accent of LuLing. Her Chinese accent is further ridiculed by another friend asking: "What's that gobbledy-gook-gook she’s saying?" (63). Ruth immediately replies: "She not my mother!" (63) and then she denies her mother's existence, "I don't know who she is!" (63). In fact, Ruth feels embarrassed with her mother's Chinese accent and denies recognizing her publicly. She does not feel comfortable with her Chinese ancestry which even leads her to lie about her mother. Most of the second-generation children are annoyed with their parents' preoccupation with their cultural origin. This rife of differential cultural priorities between immigrant parents and children get more intensified when the children reach in their adulthood.

In teenage, some of the second-generation immigrants become quite rebellious to lead a Western lifestyle like their White friends by defying restriction of their parents. They often: "regard their immigrant parents as lao-wan-gu (old sticks-in-the-mud or stubborn heads from the old world) and parental ways as feudal or old-fashioned-and a rebellion against tradition almost inevitably results” (Zhou 21). Apparently, Ruth begins to steal her mother's money to fulfill her needs of the teenage Western girl as Tan narrates: "when Ruth was fifteen, she began to borrow from the stash during times of her own emergencies - when she needed a dollar here and there for forbidden things: mascara, a movie ticket and later, Marlboro cigarettes” (121). At first, she becomes quite worried to repay the money. She only feels relieved after replacing the money. Later on, she feels that "she deserved the money-for mowing the lawn, washing the dishes, being yelled at for no good reason. She replaced the missing twenties with tens, then fives and eventually, just the singles wrapped with the one remaining twenty” (121). She rationalizes her stealing to follow the lifestyle of a Western girl. Children's fascination for the Western lifestyle gradually widens the rift in the intergenerational relationship in the immigrant families.

Some of the second-generation immigrants leave their parents' home and manage their lives separately in their adulthood. In The Namesake, Gogol cuts off his contact with his parents living in a condo hotel in New York and the Ratliffs' home in his adulthood. He avoids everything of his parents and absorbs into the Western culture.

He did not want to attend his father's alma mater and live in an apartment in Central Square as his parents once had and revisit the 
Family Dynamics: An Intergenerational Study 59

streets about which his parents speaks nostalgically. He didn't want to go home on the weekends, to go with them to pujos and Bengali parties, to remain unquestionably in their world. He prefers New York, a place which his parents do not know well, whose beauty they are blind to, which they fear. (Lahiri 126)

Thus, the children's desire to leading the Western lifestyle of the host country leads them to create distance from their parents who often embody the cultural values of their ancestral land.

The cultural differences between the home; Asian countries and the host country the United States play a crucial role in the intergenerational clashes in Asian immigrant families. The parents, who are brought up in the Asian countries and migrate to the diaspora mostly in their adult life, seem to be preoccupied with their being, that is, the cultural root and attempt to impose the same to their children. However, the children who are born and brought up in the diaspora, oppose the imposition of their parents and imbibe Western cultural values and lifestyle of their new land. Basically, the children want to enjoy the Western cultural values of freedom and individualism without parental intervention in their personal affairs whereas Asian American parents expect to exercise parental authority in children's lives. Such intergenerational clashes intensify when their children reach in their adulthood and gradually begin to resist their parental impositions. Another contentious issue in immigrant families is the interracial marriage and relationship. Most immigrant parents expect their children to get married within the same ethnic group to conserve their native cultural identity whereas the children give more priority on their feelings and personal desires than ethnic issue in their marriage. However, the immigrants of both generations differ in their attitude to their being; the cultural practices of the home and becoming process; the adoption of the cultural practices of the host counties. Unlike other first-generation immigrants, Keiko, in The Chorus of Mushrooms not only adopt cultural practices of her host country but also insists her daughter Murasaki to follow the Western values and lifestyle. But, the secondgeneration Murasaki opposes her mother's attempt and explores her origin. In this sense, the immigrant parents and children clash in heterogeneous manner in their cultural negotiation in the diaspora. However, they harmonize their relationship with their growing sense of maturity and flexibility to each other concerns and priorities in the diaspora.

\section{Intergenerational Dynamics: Parents-Children Reconciliation}

The parents' flexibility with the cultural practices of their host country and children's growing sense of maturity resolve various contentious issues in immigrant families. In their becoming process, parents adopt different cultural practices and values 
Family Dynamics: An Intergenerational Study 60

of the host country. Some of them even facilitate their children's assimilation into the mainstream culture of the host land. Parents' attempts of acculturation render harmonious relation in immigrant families. In the same way, the children also show their attachment with their being, that is, the cultural genealogy which renders harmonious relation with their parents. In this process, some of them even identify with their parents by following certain behavioral patterns which are deeply ingrained in their cultural origin. Moreover, some of them take up their familial responsibility of helping their parents in adversities. The immigrant parents and children resolve various contentious issues over the period of the time while involving in the cultural negotiation of their being and becoming in the diaspora.

In The Namesake, Ashima harmonizes her relation with her children by adopting cultural practices of her host country. She begins to celebrate American festivals like Christmas and Thanksgiving for the sake of her children. In such occasion, she even goes for Western food like turkey, sandwiches with bologna or roast beef for her children. Gogol recognizes in the end that it was for him and his sister "that his parents had gone to the trouble of learning these customs. It was for their sake that it had come to all this" (Lahiri 286). On the contrary, Ashima does not celebrate Thanksgiving at her home in the absence of her children. For instance, Ashima with Moushumi's mother stick with their native cultural taste of mutton instead of adopted Turkey when they are shopping in New York in the absence of their children. In this sense, their flexibility to the mainstream culture aims to harmonize their relation with their Americanized children.

In the same way, the second-generation children also harmonize their relationship with their parents by positively appreciating their being, cultural root. For instances, reading her mother's memoir, Ruth knows about her cultural and familial genealogy in The Bonesetter's Daughter. This familiarity simultaneously changes her attitude to both: her being and her mother. Then, she views herself a daughter of a courageous and resilient mother instead of taking herself as a daughter of an embarrassing Chinese lady. She sees her mother in a new light and wants to tell her: "I'm sorry and I forgive you too" (Tan 267). She also realizes that her grandmother and mother; "are the women who shaped her life, who are in her bones... They taught her to worry. But she has also learned that these warnings were passed down, not simply to scare her, but to force her to avoid their footsteps, to hope for something better” (303). In this sense, mother's life story enacts as a cultural transmitter of her ancestry and helps develop positive image about their being, cultural root. In fact, parents and grandparents contribute significantly to the negotiation of the second-generation immigrants' cultural identity by exposing with the repository of native cultural heritage.

The second-generation immigrants sometimes go beyond constraints of language to have access with the cultural heritage of their homeland. For instance, in Chorus of 
Family Dynamics: An Intergenerational Study 61

Mushrooms Murasaki involves in such extra-verbal communication with her Grandmother Naoe who channelizes family history mixing with folk tales to her. Often Naoe begins with "“"Mukāshi, mukāshi, ōmukashi,” the Japanese equivalent of "once upon a time"”' (Ponce 74) and narrates her blended stories. These Japanese fairy tales, family history and use of Japanese words revive her lost sense of cultural identity in diasporic existence. Besides, Murasaki yearns for these mysterious stories although she fails to comprehend the language in which they are told. Naoe narrates that Murasaki: "places her head in my bony lap and I begin to speak my words" (Goto 15). Naoe’s words, though she fails to understand them, connect Murasaki with her being, Japanese heritage. Naoe reflects that Murasaki: "cannot understand the words that I speak, but she can read the lines between my brow, the creases beside my mouth" (Goto15). Studying the body language and facial expression, Murasaki interprets and internalizes the stories told by her grandmother. So, children's familiarity with ancestry and cultural root does not only harmonize the familial disputes in the immigrants' families but also make them more responsible toward their family.

When they get mature, the second-generation immigrants also undertake their filial responsibilities in the time of crisis and adversities following the Eastern values of interdependence of family. Evidently, Ruth goes to live with her mother in her illness in The Bonesetter's Daughter. Being aware of: "the Chinese concept of family and filial responsibility" (Pu 13), she feels herself responsible to look after mother. So, she negates her boyfriend Art's proposal of going on holiday keeping a housekeeper to look after her mother. Obviously, Art's proposal: “violates Ruth's concept of family and upsets Ruth" (13) by reviving her Chinese cultural ancestry and notion of family. Then, leaving her American boyfriend Art's house, she goes to her mother's house to look after her mother. She realizes: "I feel more myself” (Tan 263) after going to her mother's house. With this realization, she begins to look after her fragile mother sincerely. In this sense, the second-generation immigrants become quite sympathetic to their parents in their illness and identify with them. The identification with parents, in turn contributes, to explore their own being.

In their identification with their parents, the second-generation also internalize certain traits innately connected in their being, ancestry and family tradition. In The Bonesetter's Daughter, Ruth's annual muteness, in which she sees meteor shower on the twelfth of August, is mysteriously linked with her family tradition. Her mother always reminds her that the shooting stars "were really 'melting ghost bodies' and it was bad luck to see them" (Tan 11). For Ruth, the ghost is her grandmother Precious Auntie. Moreover, Precious Auntie suffers permanent muteness whereas Ruth suffers routine muteness. Thus, the 'muteness', 'ghost' and 'meteor shower' mysteriously connect Ruth and her grandmother. But, after finding her grandmother's real name is 'Liu Xin' which 
Family Dynamics: An Intergenerational Study 62

means: "Remains True,...the shooting star is actually not bad luck" (Wong 63). Ruth seems to ward off the superstitious belief and realizes that her "ability to speak is not governed by curses or shooting stars or illness" (Tan 302). Rather, it is her choice to write and not to talk at the end. Thus, Ruth "continues the family tradition of being a "doctor": while her great-grandfather is a bone doctor, she is a "book doctor"” (Wong 263). In this sense, integrating family tradition, Ruth is inextricably connected with her being; cultural origin.

Similarly, Ruth feels the stories of her mother and grandmother "as part of her own” (262). Internalizing their stories, she feels the presence of these ladies within her and guiding her in the moment of crisis. In the epilogue, she imagines that the spirit of Precious Auntie; her grandmother saying her:

Think about your intentions, "Bao Bomu says. "What is in your heart, what you want to put in others. "And side by side, Ruth and her grandmother begin. Words flow...They write about what happened, why it happened, how they can make other things happen. They write about what could have been, what still might be. (Tan 304)

Ruth envisages that "the grandmother and granddaughter are emotionally connected, despite the fact that they have never seen each other” (Wong 262). She imagines her grandmother exists simultaneously with her. Then, words follow from them together in their collaborative project of writing. Likewise, some of the second-generation immigrants manifest certain behavioral traits inherited from their parents which also contribute in harmonizing their intergenerational relationship.

Henry shares emotional restrains and endurance with his typical Korean American parents in Native Speaker. His mother believes that displaying emotion signifies certain failure. So, she does not reflect her emotional reaction on her face. About her emotional restrains, he remarks that "I thought she possessed the most exquisite control over the muscles of her face. She seemed to have the subtle power of inflection over them, the way a tongue can move air" (Lee 31). She believes in controlling her emotion opposing “American openness and emotionality” (Berner 137). Moreover, his father remains silent through the years of economic struggle, his mother's death and other traumas. In fact, "the father's personal and cultural characteristic valorized in Korean/East Asian culture, associated with uncomplaining patience, fortitude, endurance, resignation and similar traits that endow subjects with the capacity to survive extreme hardships" (Lim 52). Such family heritage and cultural background influence the behavioral pattern of Henry who often controls his emotive responses which his American wife often complains about. Sharing of such cultural traits of the home country helps foster harmonious intergenerational relationship. Likewise, parents' 
Family Dynamics: An Intergenerational Study 63

acceptance of interracial marriage of their children further reduces the rift in immigrant families.

Henry's father prefers White girlfriend of his son, unlike many first-generation immigrants who insist on marriages within same ethnic group of their children. He noticeably reacts in a positive way when he knows that his son has engaged with a White girl. Henry speculates:

He never said it, but I knew he liked the fact that Lelia was white. When I first told him that we were engaged I thought he would vehemently protest, ... but he only nodded and said he respected her and wished me luck. I think he had come to view our union logically, practically and perhaps he thought he saw through my intentions, the assumption being that Lelia and her family would help me make my way in the land. (Lee 58)

Henry's father thinks that his son's relationship with the White will uplift his social standard and enhance future prospects. In fact, "whiteness for them becomes a property they acquire vicariously by a civil union, which they think will guarantee their sure foothold in society" (Hwangbo 157). Whatever might be the latent motif, father's acceptance of the white daughter-in-law harmonizes parents-children relationship.

To sum up, immigrant parents and children attempt to resolve the intergenerational rift with parents' flexibility and children's maturity. In their becoming process in Hall's terminology, parents flexibly adopt certain practices of their host country which help them to foster harmonious relationship with their children. Some of them also accept their children's decision of the interracial marriage. Such changes in parents' attitude and behaviour help harmonize their relationship with their children. In the same way, the children explore and appreciate their being, that is, cultural root which in turn contribute in harmonizing their relationship with their parents. Some of them explore their being by identifying with their parents and sharing certain behavioral traits ingrained in their cultural root which bridges the intergenerational gap in immigrant families. Moreover, some of them responsibly cooperate with their parents in overcoming the adversities in the diaspora. Thus, parents' adoptions of the Western cultural practices and children's appreciation of their cultural root help harmonize intergenerational relationship in immigrant family.

\section{Conclusion}

In recapitulation, the intergenerational relationship in immigrant families ranges from an intense argument to mutual understanding over the period of time. Parents' preoccupation with their being; cultural root and Children's fascination with cultural practices of the host country render intergenerational conflict particularly in the families 
Family Dynamics: An Intergenerational Study 64

of the immigrants whose host and home countries differ sharply in their cultural practices. The cultural differences between the Eastern Asian culture which prioritizes on mutual dependence and parental control and the Western American cultural practices which emphasizes on individualism and freedom renders the conflict in Asian American families. Parents often tend to impose the cultural practices of their home country to their children whose responses ranges from reluctance in childhood to resistance in the adulthood. In the same way, the children in their fascination and adoption of the Western lifestyle encounter opposition from their parents. However, both parents and children gradually resolve family disputes in immigrant families by showing flexibility in their cultural priorities in diverse manner. Parents gradually adopt cultural practices of the host country and the children also explore and appreciate their cultural root in heterogeneous manner. Such changing cultural values and priorities help foster harmony intergenerational relationship in immigrant families. Basically, the dynamic process of forming the cultural identity influence intergenerational relationship in immigrants' families.

The cultural identity of immigrants involves in a constant process of negotiation between their being, cultural practices and historical experiences of their home country and their becoming process, present interaction and adoption of the cultural practices of their host country. The negotiation of the being and the becoming, the past and the present, the home and the host country and the Eastern and the Western cultural practices jointly contribute in the formation of the cultural identity of Asian immigrants in the diaspora. Their cultural identities involve in constant process of formation and reformation while negotiating in the diaspora. As a result, the immigrants constantly vacillate between the cultural practices of their host and home countries. This vacillations influence intergenerational relationship in immigrant families. When immigrant parents and children are in the same cultural space; either in their home or host culture in their cultural negotiation, they tend to harmonize their intergenerational rift. However, their cultural negotiation is the dynamic process and they are constantly vacillating between the two cultural spaces; home and host. In this process, they are in conflicting relationship with each other when they prioritize different cultural spaces. These priorities are momentary and in a constant process of change so, they involve in a constant process of conflict and harmony in their cultural negotiation in the diaspora.

\section{Works Cited}

Anderson, Benedict. Imagined Communities: Reflection on the Origin and Spread of Anthias, Floya. “Evaluating 'Diaspora': Beyond Ethnicity?” Sociology, vol. 32, no. 3, 1998, pp. 557-580. JSTOR, www.jstor.org/stable/42855957. 
Family Dynamics: An Intergenerational Study 65

Beautell, Eva Darias. "Hiromi Goto’s Chorus of Mushrooms: Cultural Difference, Visibility and the Canadian Tradition." Revista Estudios Ingleses, vol. 16, 2003, pp. 6-48.

www.academia.edu/25808048/Hiromi_Gotos_Chorus_of_Mushrooms_cultural_ difference_visibility_and_the_Canadian_tradition.

Berner, Heike. Home is Where the Heart is? Identity and Belonging in Asian American Literature. 2003. der Ruhr-U, PhD dissertation.www brs.ub.ruhr-unibochum.de/netahtml/HSS/Diss/BernerHeike/diss.pdf.

Conrad, Tammy S. Creating an Asian American Mythology: Story Telling in Amy Tan's Fiction.1998. Texas Tech U, PhD dissertation. www.ttu-ir.tdl.org/ttuir/bitstream/handle/2346/20106/31295012829205.pdf.

Dunick, Lisa M.S. "The Silencing Effect of Canonicity: Authorship and The Written World in Amy Tan's Novels”. MELUS, vol. 31, no. 2, 2006, pp.3-20. www.uta.edu/faculty/kulesz/Engl\%203370/22885461.pdf.

Foner, Nancy. "Introduction: Intergenerational Relations in Immigrant Families.” Across Generations: Immigrant Families in America. New York U, 2009.

Foner, Nancy and Joanna Dreby. "Relations Between the Generations in Immigrant Families.” Annual Review of Sociology, vol. 37, 2011, pp. 545-564. doi.org/10.1146/annurev-soc-081309-150030.

Giguere, Benjamin. "Living at the Crossroads of Cultural Worlds: The Experience of Normative Conflicts by Second-generation immigrant Youth." Social and Personality Psychology Compass, vol. 4, no. 1, 2010, pp. 14-29.

www.spresearch.ca/bgiguere/sites/default/files/Giguere_Lalonde_Lou_2010.pdf.

Goto, Hiromi. Chorus of Mushrooms. NeWest, 1994.

Hall, Stuart." Cultural Identity and Diaspora." Colonial Discourse and Post colonial Theory: A Reader, edited by Patrick Williams and Laura Chrisman, Columbia UP, 1994, pp. 222-237.

Hobsbawm, Erik. "Introduction: Inventing Traditions.” The Invention of Tradition, edited by Erik Hobsbawm and Terence Ranger, Cambridge, 1983, pp.1-14.

Hwangbo, Kyeong. Trauma, Narrative and the Marginal Self in Selected Contemporary American Novels. 2004. Florida U, PhD dissertation. etd.fcla.edu/UF/UFE0007302/hwangbo_k.pdf.

Kedurie, Elie Nationalism. Blackwell, 1960.

Lahiri , Jhumpa. The Namesake. Harper Collins, 2006.

Lee, Chang rae. Native Speaker. Penguin, 1995.

Lim, Shirley Geek- Lin. "Money, Power and Immigrant Son in Chang rae Lee’s Native Speaker: Looking For the American Father.” Review of International American 
Family Dynamics: An Intergenerational Study 66

Studies, vol. 9, no, 2, 2016, pp. 45-69.

www.journals.us.edu.pl/index.php/RIAS/article/view/4976.

Om, Tina, Suyong. Creating Identity: An Exploration of Second-generation Asian American in The Joy Luck Club, Mona in the Promised Land And Native Speaker. 1999. California State U, Ph D dissertation.

www.researchgate.net/publication/35015765_Creating_identity_an_exploration_ of_secondgeneration_Asian_Americans_in_The_Joy_Luck_Club_Mona_in_the _promised_land_and_Native_speaker.

Petkova, Diana. "Cultural Identity in Pluralistic World.” Cultural Identity in an Intercultural Contexts, edited by Diana Petkova and Jaakko Lehtonen, U of Jyvaskylan, 2005, pp. 11-66.

Ponce, Eva, Pinch. "Memory and Language in Hiromi Goto's Chorus of Mushrooms." Language Value, vol.4, no.2, December 2012, pp. 70-88.

www.languagevalue.uji.es/index.php/languagevalue/article/view/75.

$\mathrm{Pu}$, Xiumei. Spirituality: A Womanist Reading of Amy Tan's “The Bonesetter's Daughter.” 2006. Georgia State U, PhD dissertation.

scholarworks.gsu.edu/cgi/viewcontent.cgi?article=1003\&context=wsi_theses.

Tan, Amy. The Bonesetter’s Daughter. Random, 1989.

Vizan, Iuliana. "Questioning Memory and Family History in Amy Tan's The Bonesetter's Daughter and The Hundred Secret Sense.” Language, Individual and Society, vol. 8, 2014, pp.214-226.

www.scientificpublications.net/get/1000006/1408971628729063.pdf.

Walsh, Katie. “Storytelling in Amy Tan's The Bonesetter's Daughter: Belonging and The Transnationality of Home in Order Age.” Identities; Global Studies in Culture and Power, vol. 24, no. 5, 2017, pp. 604-624. www.tandfonline.com/doi/abs/10.1080/1070289X.2017.1346508.

Wong, Cynthia F. "Asymmetries: Loss and Forgiveness in the Novels of Amy Tan.” China Fiction and English Language: Literary Essays in Diaspora, Memory, Story, edited by Robert Lee, Rodopi, 2008, pp. 57-78.

Zhou, Min. "Conflict, Coping and Reconciliation: Intergenerational Relationship in Chinese Immigrant Families.” Across Generations: Immigrant Families in America, edited by Nancy Foner, New York UP, 2009, pp. 21-46. 